¿Cómo se originaron las infecciones más importantes que afectan a los seres humanos?

Las poblaciones humanas de cazadores recolectores han sufrido por millones de años de enfermedades infecciosas (EI) similares o idénticas a las de otras poblaciones de primates. Las EI de zonas templadas parecen haberse originado abrumadoramente en el Viejo Mundo (África, Asia y Europa), mayormente de las enfermedades de los animales domésticos. Las enfermedades tropicales surgieron igualmente en el Viejo Mundo, pero por razones diferentes y no de los animales domésticos.

Los investigadores aducen que un microbio de origen animal pasa por cinco etapas hasta transformarse en uno que infecta exclusivamente al hombre. De 25 enfermedades principales analizadas por su carga mundial de morbilidad y mortalidad, 17 causan el mayor número de años de vida potencial perdidos: ocho de zona templada (hepatitis B, influenza A, sarampión, tos ferina, rotavirus A, sífilis, tétanos y tuberculosis) y nueve de los trópicos (sida, enfermedad de Chagas, cólera, dengue hemorrágico, tripanosomosis del África Occidental y del África Oriental, paludismo por Plasmodium falciparum y P. vivax, y leishmaniosis visceral). También se seleccionaron otras ocho enfermedades por su importancia en el pasado (difteria, parotiditis, plaga, rubéola, viruela, fiebre tifodea y tifus, más la fiebre amarilla) si bien la medicina moderna y la salud pública las han erradicado o reducido mucho. No todos los microorganismos pasan por las cinco etapas y muchos se atascan en una. La transición de la etapa 1 a la 2 (cuando el microbio confinado a los animales primero infecta al hombre) es crítica y difícil de entender. Ejemplo son los plasmodios, que provienen de un hospedador o grupo estrechamente relacionado. En la etapa 2 están los ya transmitidos al hombre pero no entre humanos, como carbunco, tularemia, Nipah, rabia y virus del Nilo Occidental. La etapa 3 describe microorganismos que pasan por unos cuantos ciclos de transmisión secundaria entre humanos, pero los brotes se extinguen pronto, como las virosis de Ébola y Marburgo, y la viruela de los simios. En la etapa 4, la enfermedad tiene un ciclo natural selvático en que el hospedero infecta al hombre pero también tiene largas secuencias de transmisión solo entre humanos. En la enfermedad de Chagas, el ciclo selvático es más importante que el contagio entre humanos. En el dengue, tanto el ciclo selvático como el humano son de igual importancia en ciertas zonas del Asia y África. Sin embargo, en casos como la influenza A, el cólera, el tifus y la tripanosomosis del África Occidental, la enfermedad ha llegado a extenderse principalmente entre los humanos. Ya en la etapa 5, el microorganismo se dedica exclusivamente al hombre, como la malaria por Falciparum, sarampión, parotiditis, rubéola, viruela y sífilis.

En zonas tropicales, la mayor parte de las enfermedades son transmitidas por insectos, lo que podría atribuirse a la variación de actividad estacional. Por otra parte, en las zonas templadas es más común que las infecciones impartan inmunidad. Estas son por lo general agudas más bien que lentas, crónicas o latentes. El paciente se recupera o muere en dos o tres semanas. Una mayor proporción de las enfermedades de zona templada analizadas están en etapa 5 y hay pocas en las etapas 2 o 3.

Los estudios epidemiológicos permiten estimar el tamaño de población necesario para sostener una enfermedad "de las masas". Para el sarampión, la rubéola y la tos ferina, se requieren varios cientos de miles de personas, poblaciones que no existían hasta que comenzó la etapa agricultural hace unos 11000 años. Las enfermedades epidémicas de zonas templadas tienen que haber evolucionado a partir de entonces; la difteria, influenza A, sarampión, rotavirus, viruela y tuberculosis, de animales domésticos; la hepatitis B, plaga y tifus, de primates y roedores; y la rubéola, sífilis, tétanos y fiebre tifoidea, de origen desconocido.

Como efectos importantes de esas enfermedades, su origen en el Viejo Mundo facilitó la conquista europea de los habitantes de las Américas y de las islas del Pacífico. Muchos más amerindios murieron por enfermedad que por heridas de espada o de bala. Además, las EI han ejercido notables fuerzas selectivas en nuestros genomas.

A pesar de que sabemos que la historia se seguirá repitiendo, todavía no existe ningún plan mundial para monitorear nuevos agentes patógenos que pasan de los animales al hombre. Un plan así ayudaría a describir la diversidad de agentes microbianos a que estamos expuestos, caracterizar los agentes patógenos de animales que podrían ser una amenaza, y quizá detectar y controlar a nivel local alguna situación peligrosa. (Wolfe ND, Dunavan $\mathrm{CP}$, Diamond J. Origins of major human infectious diseases. Nature. 2007;447:279-283.)

\section{La situación actual de la malaria}

A pesar de que ha pasado más de un siglo desde que se descubrieron las causas del paludismo, todavía no se cuenta con una cura contra la certera picada de la anofeles hembra cuando llega repleta de esporozoitos de plasmodios $y$, mientras se alimenta de sangre para nutrir sus huevos, inyecta los parásitos, que se apresuran a alojarse en los hepatocitos de la víctima. La malaria hoy día 
afecta al mayor número de personas jamás conocido en la historia y es endémica en 106 países. Amenaza a media humanidad y su increíble adaptabilidad le ha mantenido con nosotros desde el principio de nuestra vida en la tierra. Es posible que los dinosaurios tuvieran malaria, pues se sabe que afecta a los pájaros, puercoespines, monos, serpientes y ardillas voladoras, entre otras especies. Las momias egipcias muestran signos de paludismo, Hipócrates documentó las etapas de la enfermedad y es posible que esta enviara al otro mundo a Alejandro el Grande.

Según datos de la OMS, uno de los peores focos del mundo existe en Zambia, donde a diario mueren cerca de 3000 niños, uno cada 30 segundos. En algunas provincias, más de una tercera parte de los menores de 5 años tienen la enfermedad. En la India y Sri Lanka, después de los monzones, el agua tarda en drenar mientras quedan millares de charquitos ideales para la cría de mosquitos. En la región amazónica del Perú a lo largo de la nueva carretera Iquitos-Nauta, en lo que había sido selva virgen intacta, hay ahora criaderos de peces, los árboles se cortan para hacer carbón y cada vez hay más enfermos de paludismo. La falta de los árboles permite que la luz solar caliente los charcos transformándolos en criaderos de mosquitos. En menos de 10 años, los casos de malaria en el Perú han aumentado de cientos a más de 120000 al año.

En realidad, el paludismo estuvo a punto de desaparecer. Las naciones desarrolladas consiguieron desembarazarse de la enfermedad, de modo que mucha gente tiene la falsa impresión de que es un problema resuelto, como la viruela o la poliomielitis. El primer remedio conocido fue la quinina, en Ecuador y lo que es hoy Perú. Dos siglos más tarde, ese árbol se estableció en India, Sri Lanka y Java, pero no era un remedio ideal, pues causaba sordera. En el decenio de 1940, se creó una maravillosa medicina sintética: la cloroquina. Casi al mismo tiempo se inventó el DDT y con esas dos armas la OMS inició una gran lucha contra la malaria. En 1946 se crearon los Centros para el Control de Enfermedades específicamente para combatir el paludismo. Para 1950, la transmisión de la malaria se había interrumpido en los Estados Unidos, gran parte del Caribe, Taiwán y los países balcánicos. En Sri Lanka, donde había 2,8 millones de enfermos de malaria en 1946, en 1963 quedaban 17. En la India pasaron de 800000 al año a casi cero. Pero, la campaña era cara y su apoyo se abandonó en 1969. La malaria recrudeció.

En 2007 morirán por esa causa al menos un millón de personas, más del doble que hace una generación. El paludismo es una plaga de los pobres, que contribuye a la pobreza del país, lo que también contribuye a que se pase por alto. En los últimos años, la OMS ha insistido en que la reducción de esta enfermedad sea una prioridad mundial. Se han donado y prometido miles de millones de dólares para combatirla y los fondos con que se contaba se han duplicado desde el 2003 en adelante. Se está tratando de combinar cuanta técnica antipalúdica se conoce: remedios chinos a base de hierbas, mosquiteros tratados con insecticidas y "cocteles" ultramodernos de múltiples drogas. Al mismo tiempo, hay varios grupos estudiando la posibilidad de una vacuna.

De las cuatro especies de parásitos maláricos que infectan al hombre, la más virulenta es Plasmodium falciparum, responsable anualmente de cerca de la mitad de los casos mundiales y de $95 \%$ de las muertes. Es la única forma de malaria que afecta al cerebro $\mathrm{y}$, tan fulminante $\mathrm{y}$ temida, que un joven puede estar jugando fútbol por la mañana y morir por la noche. Sobre todo, puede que haya afectado a los enormes números de niños que la han tenido. En 2005, una encuesta reveló que por cada 1000 menores de 5 años en el noroeste de Zambia había 1353 casos de malaria. No se trata de un error matemático (mayor de 100\%), sino de que muchos niños se infectan repetidas veces. Hoy día un gran problema es la resistencia del plasmodio a los medicamentos, pues evoluciona con tanta rapidez. Por el momento en Zambia se ha conseguido generalizar el uso de mosquiteros, lo que ha reducido un poco el número de muertes. (Finkel M. Bedlam in the blood: malaria. National Geographic. 2007; 212(1):32-67.)

\section{Métodos de encuesta para lugares o circunstancias difíciles}

Las encuestas de salud son un instrumento de gran importancia en la caja de herramientas de los epidemiólogos, pues desempeñan la función crítica de medir la salud de una población, especialmente en los países en desarrollo. Para evaluar los objetivos de desarrollo del milenio se requieren estudios en gran escala como las encuestas demográficas y de salud, las de indicadores múltiples por conglomerados y las que miden el nivel de vida. La ejecución de intervenciones internacionales para la salud - prevención de enfermedades, atención curativa, ayuda de urgencia, fortalecimiento del sistema sanitario- tiene que ser vigilada por medio de encuestas de población. Por supuesto que las encuestas también proveen medidas directas de los resultados y su impacto sobre la población objetivo y ponen de relieve diferenciales importantes de exposición o riesgo de enfermedad dentro de conglo- 